Research Article

\title{
Knowledge, attitude and practice of prescribing antioxidants in patients with hypertension amongst practicing physicians
}

\author{
Monali Pradeep Vakharia*, Vijay Ramkrishna Zad, Nishikant Nandlal Mankar, \\ Pratik Pradeep Wadivkar
}

\begin{abstract}
Department of Pharmacology, Dr. V. M. Govt. Medical College, Solapur, Maharashtra, India
\end{abstract}

Received: 20 April 2016

Revised: 06 June 2016

Accepted: 09 June 2016

*Correspondence to:

Dr. Monali Pradeep Vakharia,

Email: monalivakharia@ yahoo.in

Copyright: (C) the author(s), publisher and licensee Medip Academy. This is an openaccess article distributed under the terms of the Creative Commons Attribution NonCommercial License, which permits unrestricted noncommercial use, distribution, and reproduction in any medium, provided the original work is properly cited.

\begin{abstract}
Background: By altering the balance in the vascular endothelium between vasoconstrictors such as thromboxane and vasodilators such as nitric oxide, reactive oxygen species contribute to endothelium-dependent vasoconstriction and increased vascular resistance which is an important contributor to the pathogenesis of hypertension. Supplementation with antioxidants, including vitamin $\mathrm{C}$, E, or B6, thiols such as lipoic acid and cysteine, and the quinone enzyme Q10, have been shown to lower blood pressure in animal models and humans with essential hypertension. The objective of this study was to assess knowledge and attitude of practicing physicians regarding use of antioxidants in patients with hypertension and to assess prescribing practices of antioxidants amongst these physicians.

Methods: It was a cross-sectional questionnaire based study conducted amongst general practitioners, physicians, cardiologists and diabetologists in Solapur from 1 October 2015 to 30 October 2015. A total of 30 doctors were interviewed using a predesigned validated questionnaire.

Results: Out of 30 doctors questioned, $24(80 \%)$ doctors were aware of the role of oxidative stress in hypertension and $70 \%$ of doctors believed in prescribing antioxidants and its positive results on blood pressure. Only 10 (33.33\%) doctors were actually prescribing antioxidants.

Conclusions: At present, antioxidant vitamins are the feasible treatments for oxidative stress in humans and should be used more frequently by doctors. It is crucial that we consider the implications of trial design and execution, and further investigation of cellular pro-and antioxidant mechanisms is critical.
\end{abstract}

Keywords: Antioxidants, Hypertension, Reactive oxygen species

\section{INTRODUCTION}

Hypertension reigns as a leading cause of cardiovascular morbidity and mortality worldwide. ${ }^{1}$ While a multitude of genetic and environmental factors contribute to this complex disease, excessive reactive oxygen species have emerged as a central common pathway by which disparate influences may induce and exacerbate hypertension. ${ }^{1}$ Oxidative stress has been implicated in various pathologies, including hypertension, atherosclerosis, diabetes, and chronic renal disease. ${ }^{2}$ By altering the balance in the endothelium between vasoconstrictors such as thromboxane and isoprostanes and vasodilators such as nitric oxide, reactive oxygen species contribute to endothelium-dependent vasoconstriction and increased vascular resistance. Oxidative stress raises blood pressure by promoting functional nitric oxide deficiency (through no inactivation and tetrahydrobiopterin depletion) and by augmenting arachidonic acid oxidation and formation of vasoconstrictive prostaglandin F $2 \alpha{ }^{3}$ Further, a significant body of epidemiological 4 and clinical trial data suggest that diets known to contain significant concentrations of naturally occurring antioxidants appear to reduce blood pressure and may reduce cardiovascular risk. ${ }^{1,5,6}$ Supplementation with antioxidants, including vitamin $\mathrm{C}$, $\mathrm{E}$, or B6 have been shown to lower blood pressure in animal models and humans with essential hypertension. ${ }^{3}$ 
The objective of this study was to assess knowledge and attitude of practicing physicians regarding use of antioxidants in patients with hypertension and to assess prescribing practices of antioxidants amongst these physicians.

\section{METHODS}

Table 1: Knowledge in physicians about prescribing antioxidants in patients with hypertension.

\begin{tabular}{|lll|}
\hline Question & Yes (\%) & No $(\%)$ \\
\hline $\begin{array}{l}\text { Whether there exists any } \\
\text { correlation between oxidative } \\
\text { stress and hypertension }\end{array}$ & 80 & 20 \\
\hline $\begin{array}{l}\text { Whether antioxidants can be } \\
\text { used in hypertension as an } \\
\text { adjuvant treatment }\end{array}$ & 63.33 & 36.67 \\
\hline $\begin{array}{l}\text { benefits of antioxidant use in } \\
\text { hypertension }\end{array}$ & 53.33 & 46.67 \\
\hline $\begin{array}{l}\text { Risks of antioxidant use in } \\
\text { hypertension }\end{array}$ & 23.33 & 76.67 \\
\hline
\end{tabular}

Table 2: Attitude of physicians for prescribing antioxidants.

\begin{tabular}{|lll|}
\hline Questions & Yes (\%) & No (\%) \\
\hline $\begin{array}{l}\text { Antioxidants are clinically } \\
\text { effective }\end{array}$ & 70 & 30 \\
\hline $\begin{array}{l}\text { Need to include antioxidants in } \\
\text { standard treatment protocol for } \\
\text { hypertension }\end{array}$ & 66.67 & 33.33 \\
\hline $\begin{array}{l}\text { Preference of natural sources } \\
\text { over commercial preparations }\end{array}$ & 60 & 40 \\
\hline $\begin{array}{l}\text { Commercially available } \\
\text { antioxidants are expensive }\end{array}$ & 83.33 & 16.67 \\
\hline $\begin{array}{l}\text { More frequent prescription of } \\
\text { antioxidants if cheaper generics } \\
\text { are available }\end{array}$ & 70 & 30 \\
\hline
\end{tabular}

Table 3: Practice of prescribing antioxidants.

\begin{tabular}{|lll|}
\hline Questions & Yes (\%) & No (\%) \\
\hline Do you prescribe antioxidants & 33.33 & 66.67 \\
\hline $\begin{array}{l}\text { Do you prescribe antioxidants } \\
\text { for hypertensive patients }\end{array}$ & 13.33 & 86.67 \\
\hline $\begin{array}{l}\text { Significant difference in } \\
\text { outcome- antihypertensives } \\
\text { alone versus antihypertensive }+ \\
\text { antioxidants }\end{array}$ & 10 & 90 \\
\hline
\end{tabular}

It was a cross-sectional questionnaire based study conducted amongst general practitioners, M.D. physicians, cardiologists and diabetologists in city of Solapur from 1 October, 2015 to 30 October, 2015. A total of 30 doctors were interviewed using a predesigned validated questionnaire. Verbal consent was taken from doctors for answering the questionnaire, after explaining the objectives of the study. The questionnaire contained questions to test the knowledge of antioxidants among practitioners, their attitudes and prescribing practices (Tables 1, 2, 3). The responses were pooled together, and appropriate statistical analysis in terms of percentage comparison was done on the pooled data.

\section{RESULTS}

Our study aimed at assessing the knowledge and attitude of use of antioxidants amongst physicians and their prescribing practices of antioxidants. Total 30 filled questionnaires were received and analysed. As per our study, $80 \%$ of doctors were aware of the correlation between oxidative stress and hypertension but only $63.33 \%$ knew that antioxidants can be used in hypertensive patients as an adjuvant treatment. $53.33 \%$ of doctors were actually aware of the benefits of use of antioxidants in hypertensive patients while risks associated with its use were known to only $23.33 \%$ of doctors. Doctors were well aware of antioxidant use in cardiovascular disorders, neurodegenerative disorders and ageing with less knowledge of its use in diabetes, stress induced psychiatric disorders and idiopathic male infertility (Figure 1). Doctors were well aware of various antioxidant agents except for folic acid and flavonoids (Figure 2). Promotional literature contributed most to sources of information of various commercially available antioxidant preparations followed by internet and colleagues (Figure 3).

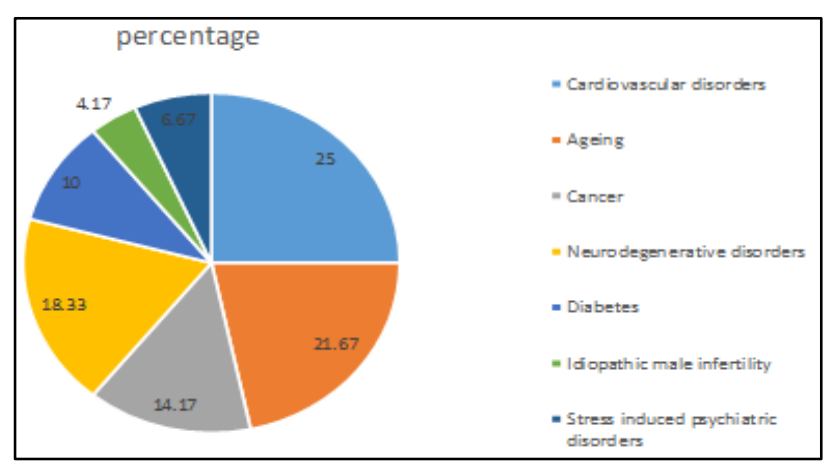

Figure 1: Knowledge in physicians about various medical applications of antioxidants.

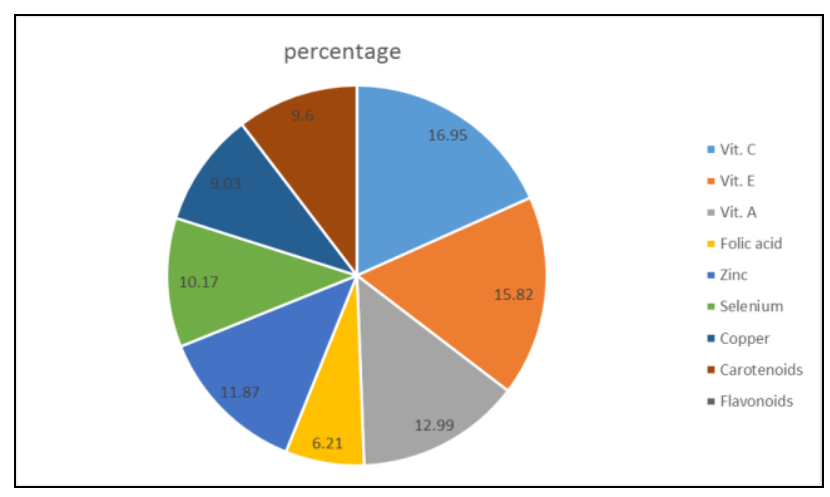

Figure 2: Knowledge in physicians about various agents acting as antioxidants. 
A total of $70 \%$ doctors felt that antioxidants are clinically effective and $66.67 \%$ felt the need to include antioxidants in standard treatment protocol for hypertension. Most of the doctors $(83.33 \%)$ found commercially available antioxidant preparations expensive and $70 \%$ were of the opinion that they can prescribe antioxidants more often if cheaper generics are made available.

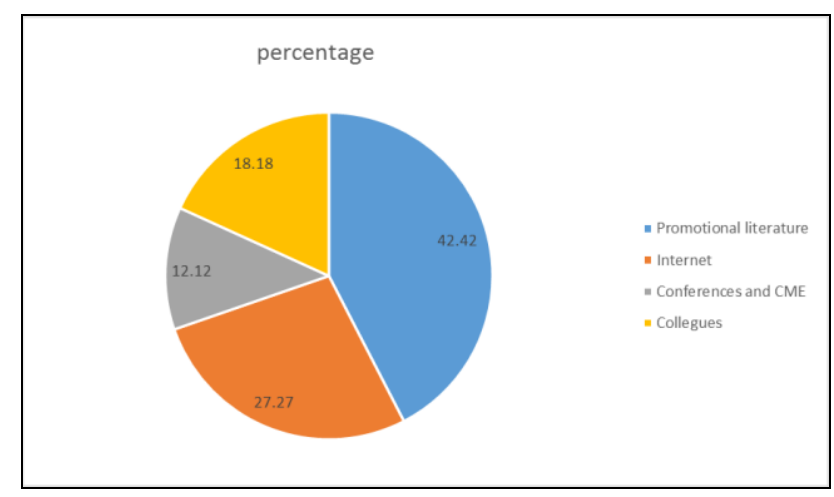

Figure 3: Sources of information of various commercially available antioxidant preparations.

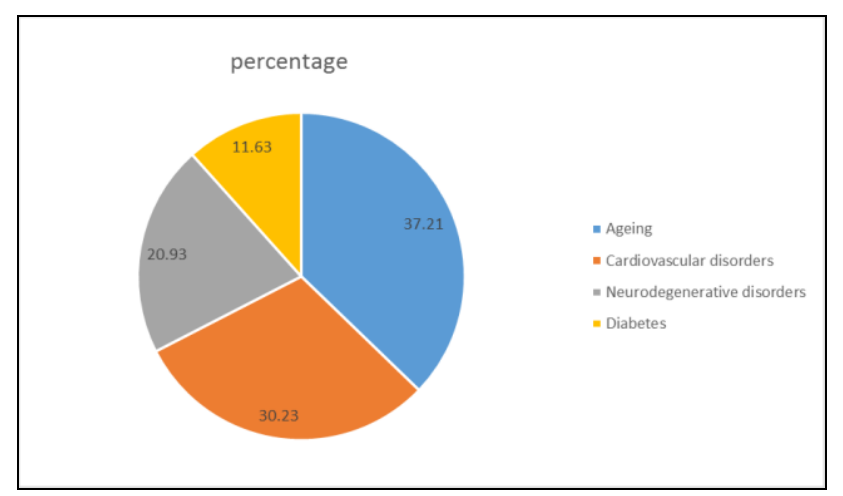

Figure 4: Practice of prescribing antioxidants in physicians for various indications.

Around $33 \%$ of doctors actually prescribe antioxidants in clinical practice for various indications; ageing being the commonest, followed by cardiovascular disorders, (Figure 4), but only $13.33 \%$ prescribed antioxidants for hypertensive patients. Out of doctors who prescribed antioxidants to hypertensive patients, $75 \%$ found significant difference in clinical outcome for patients treated with antihypertensive plus antioxidants compared to use of antihypertensive alone.

\section{DISCUSSION}

Due to lack of similar studies, results cannot be directly compared and discussed with other studies. However we have tried to discuss few aspects of our results with other studies.

According to Juraschek et al, antioxidant supplementation reduced systolic and diastolic blood pressure in short term clinical trials. ${ }^{7}$ In our study, only $13.33 \%$ doctors prescribed antioxidants for hypertensive patients. Amongst them, $75 \%$ doctors found significant difference in clinical outcome.

In a study conducted by Baradaran et al, a strong association was mentioned between blood pressure and oxidative stress. ${ }^{8}$ As per our study, $80 \%$ of doctors were aware of this co-relation however only $63.33 \%$ knew that antioxidants can be used in hypertensive patients as an adjuvant treatment.

Benefits associated with use of antioxidants have been mentioned in studies like Beg et al and Kizhakekuttu et al. ${ }^{1,3}$ In our study, $53.33 \%$ of doctors were actually aware of the benefits of use of antioxidants in hypertensive patients.

As per Bairati et al, yellowing of skin, gastrointestinal, neurologic and flu like symptoms are some of the side effects associated with antioxidant use. ${ }^{9}$ These were known to only $23.33 \%$ of doctors in our study.

In this study, we tried to include as many practicing physicians as we could meeting the eligibility criteria. To increase the sample size was beyond the scope of the study.

\section{CONCLUSION}

Despite good knowledge of antioxidant agents and their role and benefits in hypertension amongst physicians, and their positive attitude towards antioxidant use, practice of antioxidant prescription in hypertensive patients is low. This may be due to their opinion of high cost of antioxidant preparations and lack of their inclusion in standard treatment protocol for hypertension. Various reasons, including incomplete knowledge of the mechanisms of action of these agents, lack of target specificity, and potential inter-individual differences in therapeutic efficacy preclude us from recommending any specific antioxidant for antihypertensive therapy at this time. At present, antioxidant vitamins are the feasible treatment for oxidative stress in humans and should be used more frequently by doctors. It is crucial that we consider the implications of trial design and execution, and further investigation of cellular pro-and antioxidant mechanisms is critical.

\section{Funding: No funding sources Conflict of interest: None declared Ethical approval: Not required}

\section{REFERENCES}

1. Kizhakekuttu T, Widlansky M. Natural antioxidants and hypertension: promise and challenges. Cardiovasc Ther. 2010;28(4):e20-e32.

2. Muhammad S, Bilbis L, Saidu Y, Adamu Y. Effect of antioxidant mineral elements supplementation in the 
treatment of hypertension in albino rats. Oxidative Medicine and Cellular Longevity. 2012:134723.

3. Beg M, Sharma V, Akhtar N, Gupta A, Mohd J. Role of antioxidants in hypertension. Journal, Indian Academy of Clinical Medicine. 2011;12(2):122-7.

4. Dauchet L, Amouyel P, Hercberg S, Dallongeville J. Fruit and vegetable consumption and risk of coronary heart disease: a meta-analysis of cohort studies. J Nutr. 2006;136(10):2588-93.

5. Appel LJ, Moore TJ, Obarzanek E, Vollmer WM, Svetkey LP, Sacks FM, et al. A clinical trial of the effects of dietary patterns on blood pressure. DASH Collaborative Research Group. N Engl J Med. 1997;336(16):1117-24.

6. Esposito K, Marfella R, Ciotola M, Di Palo C, Giugliano F, Giugliano G, et al. Effect of a mediterranean-style diet on Endothelial dysfunction and markers of vascular inflammation in the metabolic syndrome: a randomized trial. JAMA 2004;292(12):1440-6.

7. Juraschek SP, Guallar E, Appel LJ, Miller ER. Effects of vitamin $\mathrm{C}$ supplementation on blood pressure: a meta-analysis of randomized controlled trials. The American Journal of Clinical Nutrition. 2012;95(5):1079-1088.

8. Baradaran A, Nasri H, Rafieian-Kopaei M. Oxidative stress and hypertension: possibility of hypertension therapy with antioxidants. Journal of Research in Medical Sciences: The Official Journal of Isfahan University of Medical Sciences. 2014;19(4):358-67.

9. Bairati I, Meyer F, Gelinas M, Fortin A, Nabid A, Brochet $\mathrm{F}$, et al. A randomized trial of antioxidant vitamins to prevent second primary cancers in head and neck cancer patients. JNCI J Natl Cancer Inst. 2005;97(7):481-8.

Cite this article as: Vakharia MP, Zad VR, Mankar NN, Wadivkar PP. Knowledge, attitude and practice of prescribing antioxidants in patients with hypertension amongst practicing physicians. Int J Basic Clin Pharmacol 2016;5:1349-52. 